\title{
Civicae
}

Abr a Set $2020-$ v.2 - n.2

ISSN: 2674-6646

This article is also available online at:

\section{Um relato de experiência docente: pesquisa e prática pedagógica}

Este relatório foi fruto da aplicação de quatro regências numa turma de 5o ano do ensino fundamental de uma escola municipal, localizada na cidade de Itapissuma/PE. O objetivo das práticas pedagógicas é levar o licenciado a familiarizar-se com o campo da docência. Nesta disciplina os planos de aulas foram feitos com base nos fundamentos de língua portuguesa e história. Foi escolhido como tema principal que abordassem as duas disciplinas: Conhecendo minha família. Algumas atividades foram feitas com base em propostas de construção de desenhos, construção de textos descritivos com características das famílias, construção de árvores genealógica. Foram utilizados materiais como: data show, slides, livros paradidáticos, músicas, vídeos, letras de música e entre outros recursos. Sabemos que laborar na docência não é tarefa fácil nos anos iniciais, mas para quem é apaixonado por essa área é gratificante.

Palavras-chave: Prática docente; Fundamentos da língua portuguesa; Fundamentos de história; Regência; Experiência docente.

\section{An account of teaching experience: research and pedagogical practice}

This report was the result of the application of four regencies in a class of 5th grade of elementary school in a municipal school, located in the city of Itapissuma/PE. The purpose of pedagogical practices is to take the graduate to become familiar with the field of teaching. In this discipline the lesson plans were made based on the fundamentals of Portuguese language and history. It was chosen as the main theme to address both disciplines: Knowing my family. Some activities were done based on proposals for the construction of drawings, construction of descriptive texts with characteristics of families, construction of family trees. Materials such as: data show, slides, educational books, music, videos, lyrics and other resources were used. We know that working in teaching is not an easy task in the early years, but for those who are passionate about this area it is rewarding.

Keywords: Teaching practice; Fundamentals of the Portuguese language; Fundamentals of history; Regency; Teaching experience.

Topic: Ensino Superior, Pesquisa e Extensão

Reviewed anonymously in the process of blind peer.
Received: 05/04/2020

Approved: $20 / 07 / 2020$

Mariana do Nascimento Silva (iD)

Universidade Federal de Pernambuco, Brasil

http://lattes.cnpq.br/8452449216022140

http://orcid.org/0000-0003-4733-3913

marianadonascimento92@hotmail.com

Referencing this:

SILVA, M. N.. Um relato de experiência docente: pesquisa e prática pedagógica. Justitia Liber, v.2, n.2, p.1-7, 2020. DOI: http://doi.org/10.6008/CBPC2674-6646.2020.002.0001 


\section{INTRODUÇÃO}

Este relatório final foi apresentado à disciplina de PPP4 - Pesquisa e Prática Pedagógica, disciplina ministrada pelos professores doutores Augusto Neves (in memoriam) e Maria Lúcia. Ele teve como objetivo sintetizar como foram ministradas quatro regências aplicadas numa turma do 50 ano do ensino fundamental de uma escola municipal localizada no município de Itapissuma/PE. Antes das aplicações das regências teve três observações para conhecer a turma, familiarizar-se e entender em qual nível os alunos estavam. Estas observações foram feitas todas no turno de aula acompanhada pela professora da turma e uma vez por semana. Como tema geral proposto para as quatro aulas foi utilizado: Conhecendo minha família. Porque foi trabalhado tanto conteúdos de história como língua portuguesa. Cada regência foi utilizada um plano de aula com subtemas específicos. As atividades feitas pelos alunos foram: árvores genealógicas, textos, desenhos e entre outros.

\section{RELATO}

Para os alunos de licenciatura é comum que os trabalhos, experiências sejam voltados para escola. O objetivo das PPP é levar o discente do curso de pedagogia a familiarizar-se com o ambiente que será seu campo de trabalho no futuro. Na disciplina de PPP4 - a proposta utilizada foi para que os licenciados visitassem uma escola, escolhesse uma turma dos anos iniciais, observar-se a rotina e posteriormente aplicar quatro regências todas com plano de aula. Nesta disciplina os alunos teriam que trabalhar conjuntamente os assuntos de português e história. Foi escolhido o tema sobre família. Mas por que? Na maioria das vezes os alunos estudam história geral, história de um povo, de um país, mas não conhece sua própria história.

Pensando nesse contexto foi criada para as regências planos de aula que os alunos conhecessem sua própria história e que isso também é importante para a história de um povo, pois cada elemento tem sua importância. A seguir relato das regências.

\section{1a Regência - Subtema: descobrindo as características da minha família.}

A primeira regência foi aplicada no dia 10/06/2018, nesse dia compareceram à aula 28 alunos. A aula teve início com uma dinâmica, o objetivo dessa dinâmica foi mostrar para a turma como o barulho prejudica, causando desordem de uma forma que não se consegue ouvir o outro, aplicar as atividades planejadas e nem compreender qualquer assunto que seja. Posteriormente foi apresentado o livro: Minha família é colorida de Georgina Martins. A leitura foi feita de forma coletiva, já que o livro foi reprojetado no quadro branco.

Por que foi escolhido levar um texto literário (livro) para sala de aula com o tema família? Porque nas nossas observações, apesar da professora trabalhar com leitura não participamos dessa prática, apesar de ter uma estante com alguns livros paradidáticos de qualidade, não vimos nenhuma criança nas nossas observações chegar e pegar um livro nem que seja para folhear. Também a importância da família na formação do aluno é algo fundamental para construir o cidadão e conhecer características dos nossos familiares é algo primordial para compreendermos de onde vimos quem são nossos familiares, como vivem, 
do que gostam, isso tudo ajuda a compreender nossa identidade.

Então quisemos levar para a sala de aula um pouco mais de leitura no dia a dia. Fazer com que a leitura faça parte do cotidiano deles na sala de aula e na vida, de forma prazerosa, fazendo sentido. Conhecer nossa origem é algo fundamental para entendermos nosso passado, quem são nossos ancestrais? Qual é a nossa origem? Por que não sou igual ao meu pai? Ou minha mãe? Apesar de formamos uma família, possuímos características diferentes, e isso que nos fazem sermos único e importante.

Após a leitura do livro, fizemos a socialização do tema com a turma. A atividade proposta e avaliativa foi para eles desenhassem como é sua família, e quais características cada componente tem, com quem me pareço? Isso tudo foi mostrado no livro, e tinha que ser representado no papel.

Depois ao terminar a atividade convidamos alguns alunos para socializarem seus desenhos. Algumas perguntas: o que foi que você desenhou? Quem são essas pessoas? Com quem você se parece? Quais são suas características?. Ao final pedimos para que os alunos trouxessem para a próxima regência relatos de suas famílias, que entrevistassem pais, vizinhos, parentes, irmãos para socializarmos no próximo encontro. Abaixo está duas atividades feitas pelos alunos do 50 ano. São de pessoas diferentes.

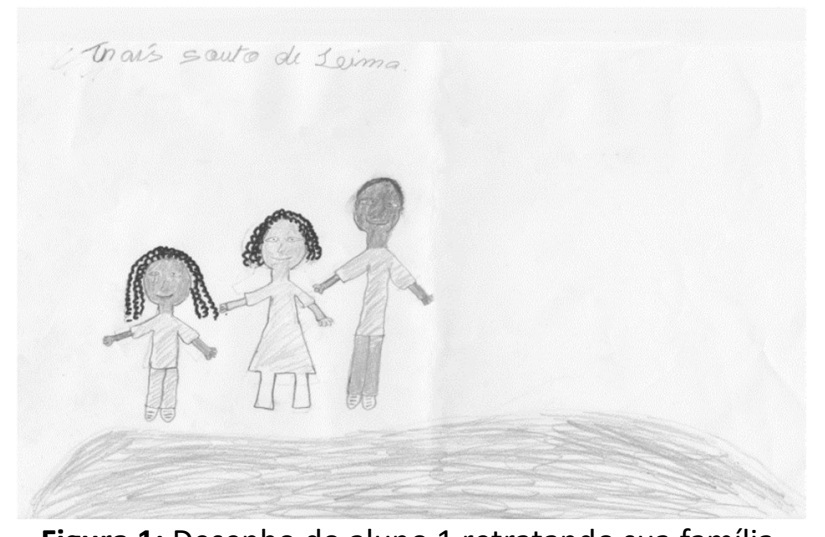

Figura 1: Desenho do aluno 1 retratando sua família.

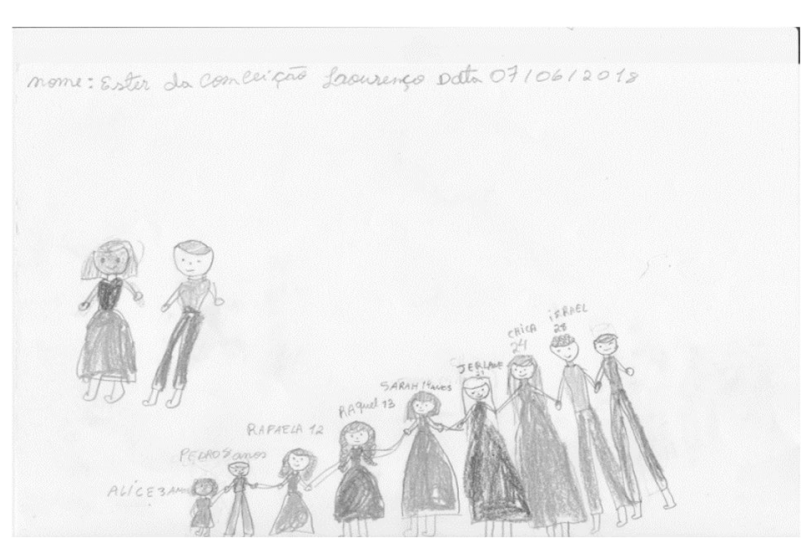

Figura 2: Desenho do aluno 2 retratando sua família.

\section{2a Regência - Subtema: Aprendendo a construir um texto descritivo a partir de relatos da família}

A segunda regência foi aplicada no dia 13/06/2018, o subtema aplicado: Aprendendo a construir um texto descritivo a partir de relatos da família. Nesse dia compareceram 28 alunos. Assim como na $1 \underline{a}$ regência a $2^{\text {a }}$ também começou com uma dinâmica. Foram formados grupos com quatro integrantes cada e uma bola por grupo, o objetivo da dinâmica era não deixar o balão cair.

No segundo foi relembrado a regência anterior, a leitura do livro: Minha família é colorida e a confecção do desenho da família. A atividade proposta neste dia foi para os alunos escrevessem um texto descritivo com as principais dos seus familiares. Foi conversado com a turma se eles sabiam características dos seus antecedentes, como: pais, avós, tios, bisavós. A maioria sabia quem era seus antecedentes, índios, negros, branco, de onde vieram, os costumes e com quem se parecia.

Foi explicado para os alunos o que é um texto descritivo e qual o objetivo desse gênero, foi pedido para que eles confeccionassem um texto descritivo com as características da sua família. Exemplo: minha família é pequena, formada por três pessoas: mamãe, papai e eu. Chamo-me João e sou um garoto pequeno, 
tenho a mistura dos meus pais. Meus olhos são azuis como o da mamãe e minha pele negra como o do papai, meus cabelos são encaracolados como os caracóis, mamãe falou que eles são iguais a do vovô.

Após a confecção dessa atividade alguns alunos socializaram seus textos para toda turma. $\mathrm{O}$ objetivo da construção do texto descritivo, foi avaliar o nível e domínio da turma com a escrita, se conseguem formar frases com coesão e coerência fazendo entender a construção de texto. Porém foi utilizada as características das famílias para que registrassem a origem dela e como são tão importantes para nossa vida. A seguir dois textos descritivos escrito pelos alunos do 50 ano do ensino fundamental.

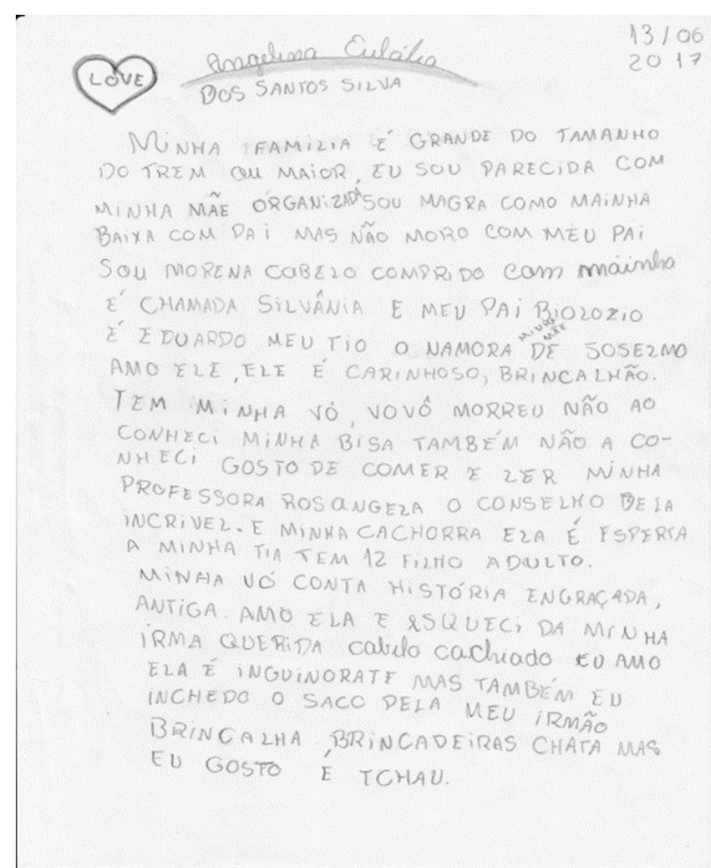

Figura 3: Texto descritivo escrito pelo aluno 3.

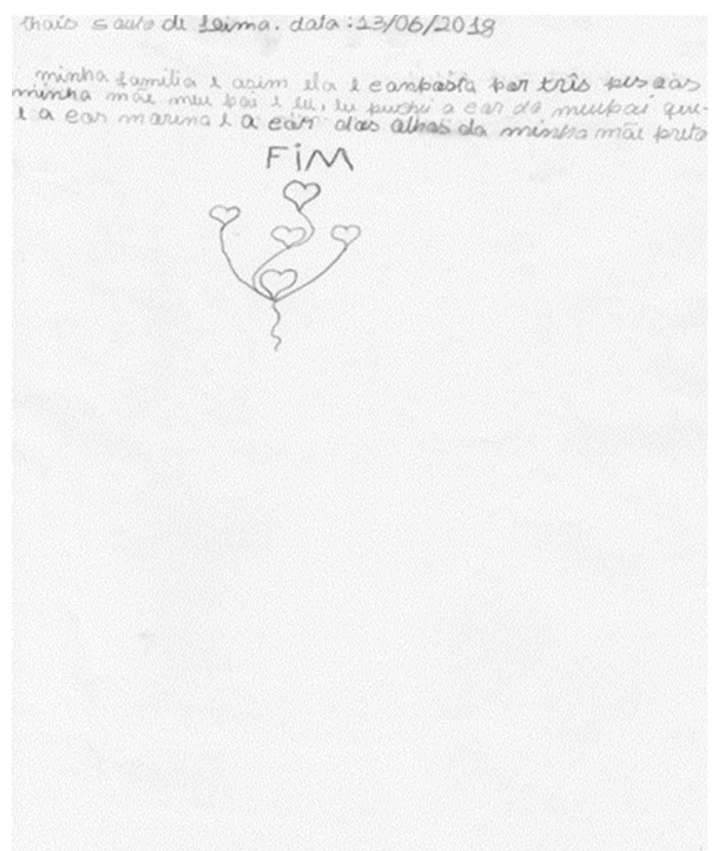

Figura 4: Texto descritivo escrito pelo aluno 4.

\section{3a Regência - Subtema: Construindo minha árvore genealógica}

A terceira regência foi aplicada no dia 14/06/2018, com vinte e oito alunos. A regência começou com conversando sobre a aula anterior, se existiriam alguns questionamentos, dúvidas possíveis, ou contribuições. Após esse momento foi passado o vídeo no Datashow da música: Eu, grupo: Palavra Cantada. Essa música retrata as características dos antepassados de uma pessoa, sua mãe nasceu num lugar, seu pai nasceu em outro, já seus avós são de outra origem.

Após todos assistirem o vídeo foi feito alguns questionamentos a respeito da mídia, para saber se eles tinham compreendido o assunto. Logo em seguida foi colocada a letra da música no quadro para que lessem em conjunto, alguns alunos leram em voz alta. Essa atividade foi feita para estimular a oralidade, leitura e compreensão de texto. Outro momento da aula foi apresentar para os alunos o conceito sobre a árvore genealógica. Algumas perguntas foram feitas, como: alunos eles sabiam o que era uma árvore genealógica? Qual o objetivo? Se já tinham feito, ou visto alguma? O que a árvore genealógica representa e para que serve?.

Foi apresentado um exemplo de árvore genealógica, com o exemplo de avós, pais, irmãos, filho e entre outros componentes familiar. Após esse momento foi distribuído uma folha de papel ofício para que 
os alunos desenhassem sua própria árvore genealógica, caso não soubesse o nome de alguns parentes deixasse com a nomenclatura (PAI, MÃE, BISAVÓ...). Essa atividade foi bem bacana, pois eles conseguiram executar. Após a atividade algumas crianças foram para frente do quadro e socializaram sua atividade com toda turma, explicando cada componente familiar. A seguir dois exemplos de árvores genealógicas confeccionados pelos alunos. Com algumas descrições.

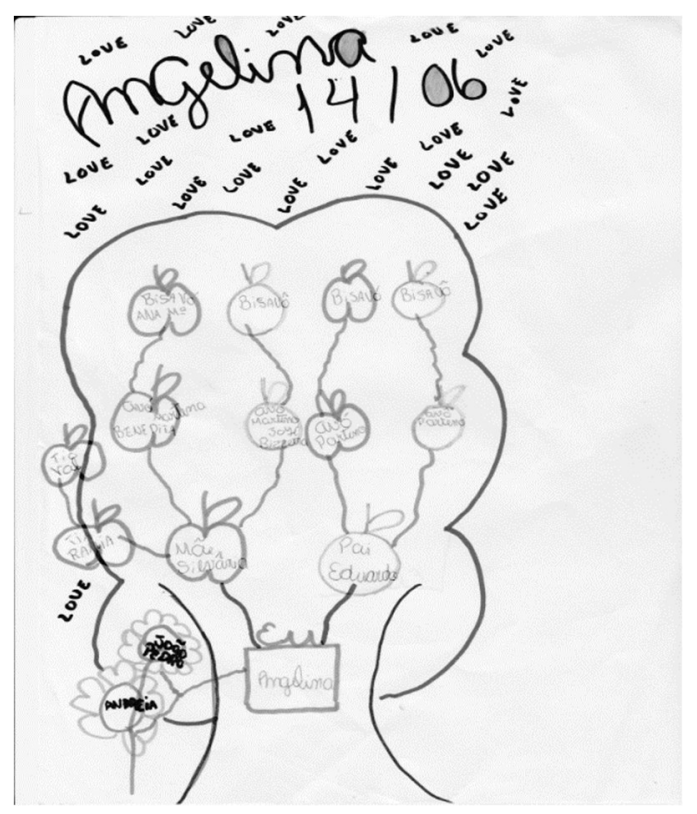

Figura 5: Confecção de árvore genealógica, aluno 5.

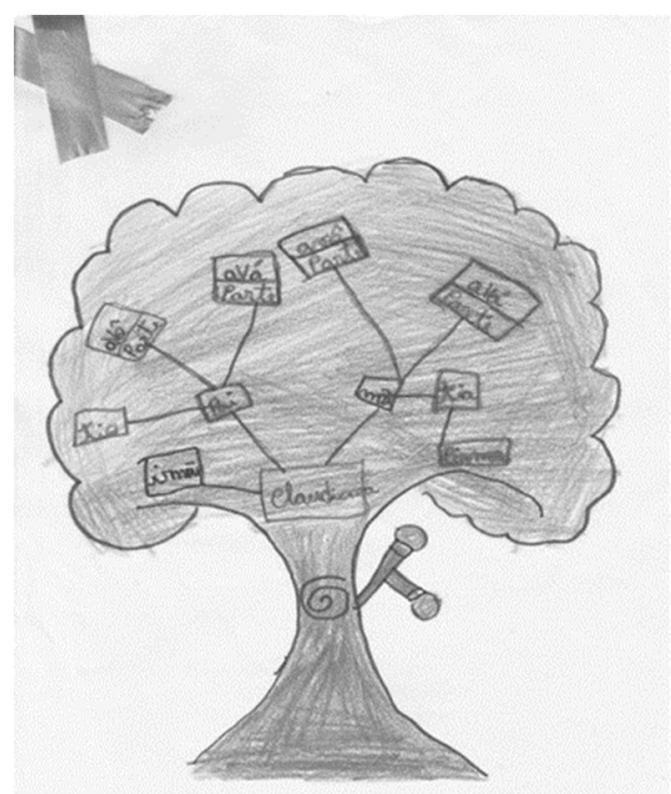

Figura 6: Confecção do aluno 6.

\section{4a Regência - Subtema: Reviver memórias antigas e construir um portfólio coletivo das atividades proposta em sala}

A última aula seria a construção em conjunto com toda turma de um portfólio com as atividades anteriores, mas infelizmente não foi possível aplicar, pois a turma estava em encerramento das atividades junina e do bimestre. Então o autor juntou todas as atividades feita pelos alunos e montou e entregou a turma, para que eles revivessem a experiência. Abaixo foto do portfólio que foi confeccionado pelo autor já que não foi possível aplicação da 4ạ regência. A princípio seria confeccionado pelos alunos.:

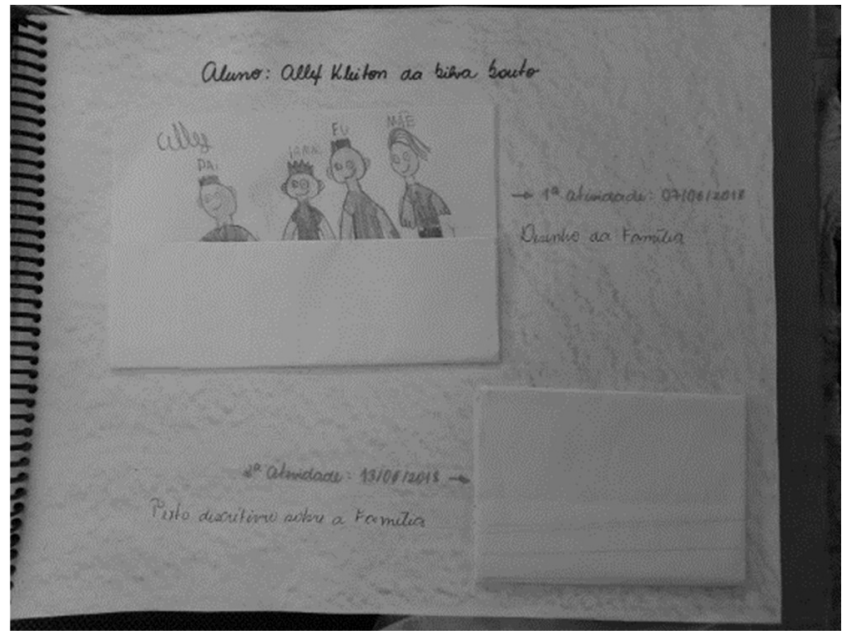

Figura 7: Portfólio confeccionado pelo autor.

Como foi dito anteriormente não foi possível a confecção do portfólio pelos alunos, porém, o autor 
montou com as atividades feitas nas três regências anteriores e entregou para a turma como uma forma de recordação com tudo que viveram.

\section{DISCUSSÃO}

Antes de ser aplicada as regências foi estudado bastante o tema a ser proposto. Para cada aula foi confeccionado um plano de aula com objetivos, conteúdo, habilidades e avaliações. Cada aula teve um subtema que se interligava com o tema principal: conhecendo minha família. Escolher verbos para elencar não é tarefa fácil. A educação no Brasil não é tarefa fácil. Há uma deficiência de infraestrutura, financeira e comportamental tanto das instituições escolares assim como seus personagens.

A disciplina de PPP4 - Pesquisa e Práticas Pedagógicas com ênfase no fundamento da língua portuguesa e fundamento da história. O discente de pedagogia deve encontrar tema que elenque tanto um como outro. Fazer essa junção é muito importante para a aula planejada faça sentido. Levar para sala de aula algo que faça sentido para o aluno deve ser algo mais comum e desafiante todos os dias. Os assuntos devem fazer sentido para aquela criança que vá para a escola com sede de saber de apreender e assimilar. Como é um relato de experiência vivida é preciso discutir mais sobre o papel da formação na docência. O professor deve estar bem preparado para dar uma boa aula e ajudar seu aluno.

\section{CONSIDERAÇÕES FINAIS}

Planejar e executar aula não é tarefa fácil, mas é muito gratificante. É difícil principalmente se sentar, planejar, conversar, estudar, observar e tentar identificar as necessidades coletivas de determinada turma, ou melhor, daquele específico grupo de alunos. Não foi uma tarefa fácil, não mesmo, porém bastante prazerosa. Quando se olhava para todos os alunos e identificava-se que eles tinham compreendido o que ali seria passar, não tem preço nem recompensa maior.

Trabalhar em sala de aula o tema do qual aborda a 'história da minha família' não é algo fácil, mas sim complexo, principalmente numa comunidade carente, que a maioria dos que ali se encontram não tem o recurso básico para sobrevivência e nem um alicerce que os sustente de valores morais e ideais (pai, mãe, responsável, parentes), onde o índice de criminalidade é altíssimo. Enfim, decidimos abordar essa temática para que todos se reconhecessem como sujeitos e protagonistas de sua própria história, que importa sim de onde vimos com quem moramos, que condições nós temos e vivemos, e que cada fator desse não interfira na nossa construção de indivíduo que temos uma história a ser contada, que essa história faz parte da construção da história maior da sociedade e que nenhuma família é igual à outra, cada uma tem suas singelas características, mas que nem por isso deixa de menos importante para o outro. Todos nós temos alguém do qual convivemos e sentimos orgulho e entender um pouco mais da nossa origem faz com compreendemos quem somos e de onde viemos.

\section{REFERÊNCIAS}

CANTADA, Palavra. Música: Eu. Álbum: Canções curiosas.

Publishing, 1998. 
KARNAL, L.. História: Sala de aula. Prática de Ensino. São Paulo: Contexto, 2015.

KLEIMAN, A. B.; MORAES, S.. Leitura e interdisciplinaridade: currículos e planejamentos. Campinas: Mercado das letras, 1999.
MARTINS, G.. Minha Família é colorida. Sm, 2015.

RITER, C.. A formação do leitor literário em casa e na escola. 1 ed. São Paulo: Biruta, 2004

A CBPC - Companhia Brasileira de Produção Científica (CNPJ: 11.221.422/0001-03) detém os direitos materiais desta publicação. Os direitos referem-se à publicação do trabalho em qualquer parte do mundo, incluindo os direitos às renovações, expansões e disseminações da contribuição, bem como outros direitos subsidiários. Todos os trabalhos publicados eletronicamente poderão posteriormente ser publicados em coletâneas impressas sob coordenação da Cognitionis Publishing, da Companhia Brasileira de Produção Científica e seus parceiros autorizados. Os (as) autores (as) preservam os direitos autorais, mas não têm permissão para a publicação da contribuição em outro meio, impresso ou digital, em português ou em tradução. 